\title{
Leisure Activity
}

National Cancer Institute

\section{Source}

National Cancer Institute. Leisure Activity. NCI Thesaurus. Code C104103.

Activities done for the purpose of relaxation or diversion from routine work. 